\title{
Outcomes of Pregnancy after Breast Cancer in Korean Women: A Large Cohort Study
}

\author{
Moo Hyun Lee, MD ${ }^{1,2}$ \\ Young Ae Kim, $\mathrm{PhD}^{3}$ \\ Jin Hyuk Hong, MPH ${ }^{3}$ \\ So-Youn Jung, MD, $\mathrm{PhD}{ }^{1}$ \\ Sunmi Lee, $\mathrm{PhD}^{4}$ \\ Sun-Young Kong, MD, PhD 5,6 \\ Boyoung Park, MD, PhD \\ Eun Sook Lee, MD, PhD ${ }^{1}$
}

\section{Purpose}

The purpose of this study was to determine the rate and outcomes of pregnancies subsequent to breast cancer in Korea, and the effect of such pregnancies on the prognosis of women who survived breast cancer and subsequently conceived.

\section{Materials and Methods}

We followed a total of 31,761 Korean women 45 years of age or younger who were treated for primary breast cancer from 2002 to 2010. We also included follow-up surveys that were conducted through December 2011. We identified recurrence and mortality from breast cancer using data linked to the Korea National Health Insurance database. We used propensity score matching of the study cohort to analyze the risks of recurrence and mortality from breast cancer depending on pregnancy.

\section{Results}

Within our sample, 992 women (3.1\%) became pregnant after receiving treatment for breast cancer. Of those, 622 (67.5\%) successfully delivered; the remaining 370 (32.5\%) failed to deliver. After propensity score matching, we found that the women who became pregnant after breast cancer did not have a different risk of recurrence (hazard ratio [HR], 0.503; $95 \%$ confidence interval [Cl], 0.434 to 0.584 ) and death ( $\mathrm{HR}, 0.520 ; 95 \% \mathrm{Cl}, 0.397$ to 0.681 ), compared with those who did not conceive after breast cancer treatment.

\section{Conclusion}

Our study is the first to report outcomes for Korean women who survived breast cancer and subsequently conceived. Women who survived breast cancer and subsequently became pregnant did not show a poorer survival outcome, compared with those who did not become pregnant.
Correspondence: Eun Sook Lee, MD, PhD Graduate School of Cancer Science and Policy Center for Breast Cancer, Research Institute and Hospital, National Cancer Center, 323 Ilsan-ro, Ilsandong-gu, Goyang 10408, Korea Tel: 82-31-920-1510

Fax: 82-31-920-1511

E-mail: eslee@ncc.re.kr

Received June 29, 2018

Accepted September 3, 2019

Published Online September 3, 2019

*Moo Hyun Lee and Young Ae Kim contributed equally to this work.
Key words

Breast neoplasms, Pregnancy, Cancer survivors 


\section{Introduction}

Although women 40 years of age or younger account for approximately $6 \%$ to $7 \%$ of breast cancer diagnoses each year in Western countries, breast cancer is the leading cause of cancer-related deaths in that population [1-3]. The proportion of Asian patients with breast cancer in that age group is reported to be much higher, at $7.6 \%$ to $12 \%[4,5]$. The average age at which women have their first child is also rising in Asian countries. As a result, health care professionals are more often confronted with questions regarding pregnancy after breast cancer treatment, including questions about the optimal timing to attempt conception, the consequences for the prognosis of the mother, and the safety of the child. Many women and their physicians are concerned about the negative prognostic effects of the high estrogen levels associated with pregnancy. However, whether breast cancer survivors should be advised against pregnancy remains to be determined. Nonetheless, $70 \%$ of young patients with cancer wish to have children after the completion of treatment [6,7].

The proportion of patients with at least one full-term pregnancy after a breast cancer diagnosis is only $3 \%$ for women younger than 45 years of age, and $8 \%$ for women younger than 35 years of age [8]. Fears related to the negative impacts of pregnancy on the evolution of breast cancer, reduced fertility derived from gonadotoxic therapy, the long duration of endocrine therapy, and the possibility of adverse obstetric outcomes may explain why those patients have such low pregnancy rates [9].

Although numerous studies have assessed the pregnancy outcomes and the prognostic impacts of pregnancy among patients with breast cancer, those topics have received little attention in Asian countries [10-17]. Studies of pregnancy outcomes subsequent to breast cancer treatment require a large number of young patients with breast cancer and a long follow-up period. We evaluated the incidence and outcomes of pregnancy after breast cancer in women of childbearing age in a large cohort of Korean women.

\section{Materials and Methods}

\section{Data sources}

We used data from the Korea National Health Insurance (KNHI) database, which were linked to cancer registration and mortality data from the Korean National Cancer Registry (KNCR) and the Korea National Statistics Office (KNSO), respectively. The KNCR is a population-based regional cancer registry in the Republic of Korea. In 2005, the KNCR began to release data collected since 1999 that was suitable for research [18]. By 2012, the completion rate for cancer registration in the KNCR reached $97.7 \%$ [19]. Since the implementation of the National Health Insurance Act in 1989, almost $97 \%$ of the Korean population has been subject to compulsory health insurance provided by the KNHI. The KNHI currently manages the entire health claims database in Korea and provides research data on enrollees, sampled using a proportional allocation method with adherence to a strict confidentiality policy. The KNHI, KNCR, and KNSO databases have been used for epidemiologic studies in the past and are considered to be of high quality [20-24]. We also conjugated this linked database to define our study variables. For example, the variables for cancer type, cancer diagnosis date, and breast cancer incidence were extracted from the KNCR database; the variables for pregnancy status, pregnancy outcomes, treatment of breast cancer, and dates of recurrence were extracted from the KNHI database. The variables for cause and date of death were extracted from the KNSO database. Specific information regarding the databases used in this study are available elsewhere [25].

\section{Identification of the study population}

Data for a population of women who received a first-time breast cancer diagnosis (International Classification of Diseases, tenth revision [ICD-10] code C50) were extracted from the KNCR for the period of January 1, 2002 to December 31, 2010. We excluded patients who were male, who had multiple primary cancers, and whose age at diagnosis was $>45$ years. Use of the KNHI database allowed us to exclude patients who did not visit the hospital and who did not have breast cancer surgery. Patients with an unknown pregnancy result were also excluded. A total of 31,761 participants were selected for this retrospective, population-based cohort study (Fig. 1).

We grouped the study population into two categories depending on pregnancy status. We identified patients with an ICD-10 code beginning with "O" as pregnant individuals and those without such an ICD-10 code during the followup period as non-pregnant individuals. We further divided the pregnant individuals into two groups depending on the pregnancy outcome: successful delivery and failed to deliver. We defined breast cancer recurrence in the study population as conditions requiring a new regimen of chemotherapy or endocrine therapy (e.g., aromatase inhibitor or fulvestrant), $\geq 1$ year after the initial breast surgery or adjuvant chemotherapy. Recurrence-free survival was defined as the period from the date of breast cancer diagnosis to the date of recurrence event. Overall survival was defined as the period from the date of breast cancer diagnosis to the date of death from 


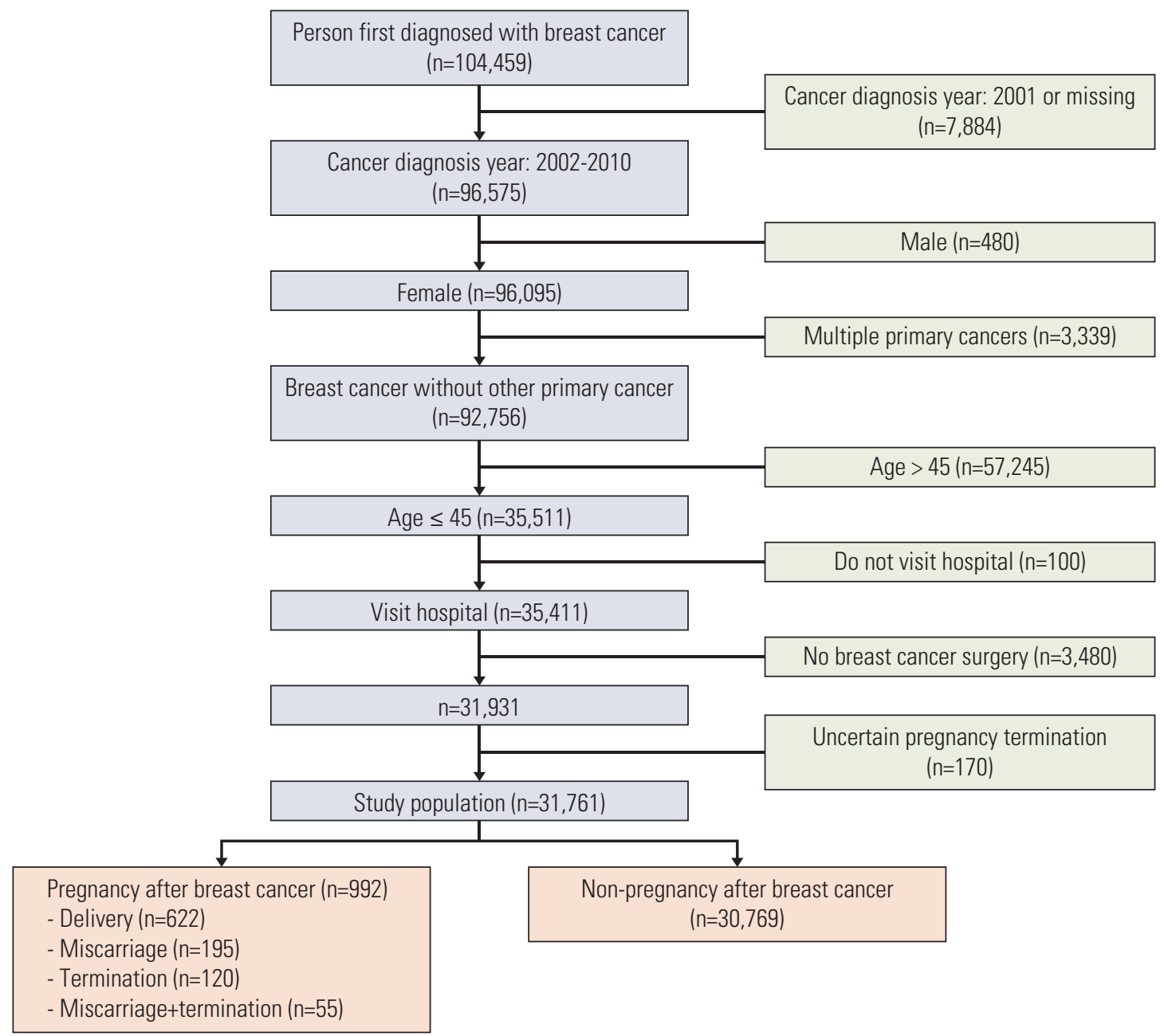

Fig. 1. Diagram of patient recruitment for the study.

any cause.

\section{Statistical analysis}

We used chi-square tests and independent $t$ tests to compare categorical and continuous variables, respectively. We also used 1:1 propensity score matching analysis [26] of the study cohort to reduce the effects of bias on the estimation of treatment between pregnant and non-pregnant individuals; this bias had the potential to affect the results for recurrence and survival. For this matching, we used the statistical software package 'matchit' of $\mathrm{R}$, and controlled the variables for age at breast cancer diagnosis, adjuvant hormonal therapy, chemotherapy, and radiotherapy for the propensity score matching. We compared the overall recurrence and survival rates between the pregnant and non-pregnant groups using the Kaplan-Meier method. Finally, we used Cox proportional hazards regressions to estimate the hazard ratios (HRs) and 95\% confidence intervals (95\% CIs) for the relationship between pregnancy and survival. We considered p-values of $<0.05$ to be statistically significant. We performed all analyses using SAS ver. 9.4 (SAS Institute Inc., Cary, NC); R was implemented in RStudio ver. 1.1.414 (RStudio Inc., Boston, MA).

\section{Ethical statement}

Our study was approved by the Institutional Review Board at the National Cancer Center in the Republic of Korea (NCC2015-2017) and was exempt from the requirement of informed consent because all of the information in the dataset is anonymous. 
Table 1. Baseline characteristics of the study population

\begin{tabular}{|c|c|c|c|c|}
\hline & $\begin{array}{l}\text { Pregnancy after } \\
\text { breast cancer } \\
(\mathbf{n}=992)\end{array}$ & $\begin{array}{l}\text { Non-pregnancy } \\
\text { after breast cancer } \\
\qquad(\mathrm{n}=30,769)\end{array}$ & p-value & $\underset{(n=31,761)}{\text { All }}$ \\
\hline Age at cancer diagnosis (yr) & $31.8 \pm 4.5$ & $39.6 \pm 4.5$ & $<0.001$ & $39.3 \pm 4.7$ \\
\hline$\leq 35$ & $788(79.4)$ & $5,722(18.6)$ & $<0.001$ & $6,576(20.5)$ \\
\hline $36-45$ & $204(20.6)$ & $25,047(81.4)$ & & $25,355(79.5)$ \\
\hline Age at time of pregnancy $(y r)($ missing $=30,769)$ & $35.4 \pm 4.4$ & - & - & $35.4 \pm 4.4$ \\
\hline$<35$ & $484(48.8)$ & - & - & $484(48.8)$ \\
\hline$\geq 35$ & $508(51.2)$ & - & & $508(51.2)$ \\
\hline $\begin{array}{l}\text { Difference between pregnancy age of patients } \\
\text { and age at cancer diagnosis (yr) }\end{array}$ & $3.60 \pm 2.00$ & - & - & $3.60 \pm 2.00$ \\
\hline Person year (yr) & $5.92 \pm 2.33$ & - & & $4.92 \pm 2.55$ \\
\hline \multicolumn{5}{|l|}{ Chemotherapy } \\
\hline Yes & $318(32.1)$ & $10,818(35.2)$ & 0.044 & $11,136(35.1)$ \\
\hline No & $674(67.9)$ & $19,951(64.8)$ & & $20,625(64.9)$ \\
\hline \multicolumn{5}{|l|}{ Radiotherapy } \\
\hline Yes & $702(70.8)$ & $21,044(68.4)$ & 0.113 & $21,746(68.5)$ \\
\hline No & $290(29.2)$ & $9,725(31.6)$ & & $10,015(31.5)$ \\
\hline \multicolumn{5}{|l|}{ Ovarian preservation (missing $=20,625$ ) } \\
\hline Yes & $2(0.2)$ & $128(0.4)$ & 0.090 & $130(0.4)$ \\
\hline No & $316(31.9)$ & $10,690(34.7)$ & & $11,006(34.7)$ \\
\hline \multicolumn{5}{|l|}{ Trastuzumab therapy } \\
\hline Yes & $13(1.3)$ & $1,058(3.4)$ & $<0.001$ & $1,071(3.4)$ \\
\hline No & $979(98.7)$ & $39,711(96.6)$ & & $30,690(96.6)$ \\
\hline \multicolumn{5}{|l|}{ Adjuvant hormonal therapy } \\
\hline Yes & $366(36.9)$ & $18,768(61.0)$ & $<0.001$ & $19,134(60.2)$ \\
\hline No & $626(63.1)$ & $12,001(39.0)$ & & $12,627(39.8)$ \\
\hline \multicolumn{5}{|l|}{ Hormone therapy duration (day) } \\
\hline Mean \pm SD & $1,061.9 \pm 709.9$ & $1,241.2 \pm 560.6$ & $<0.001$ & $1,237.8 \pm 564.4$ \\
\hline Median & 1,059 & 1,355 & & 1,349 \\
\hline \multicolumn{5}{|l|}{ Time between surgery and conception (day) } \\
\hline Mean \pm SD & $1,176.4 \pm 868.6$ & - & $<0.001$ & $1,176.4 \pm 868.6$ \\
\hline Median & 1,061 & - & & 1,061 \\
\hline \multicolumn{5}{|l|}{ SEER stage (missing=8,936) } \\
\hline Localized & $341(34.4)$ & $11,102(36.1)$ & $<0.001$ & $11,443(36.0)$ \\
\hline Regional & $183(18.5)$ & $8,417(27.4)$ & & $8,600(27.1)$ \\
\hline Distant & $9(0.9)$ & $539(1.75)$ & & $548(1.7)$ \\
\hline Unknown & $74(7.5)$ & $2,160(7.0)$ & & $2,234(7.0)$ \\
\hline Missing & $385(38.8)$ & $8,551(27.8)$ & & $8,936(28.1)$ \\
\hline
\end{tabular}

Values are presented as mean \pm SD or number $(\%)$. SD, standard deviation; SEER, Surveillance, Epidemiology, and End Results.

\section{Results}

\section{Clinical characteristics of the study cohort}

The study cohort included 31,761 women 45 years of age or younger with primary breast cancer. Among them, 992 women $(3.1 \%)$ had become pregnant after receiving treat- ment for breast cancer. The median time from breast cancer diagnosis to pregnancy was 1,153 days. The median age at the time of conception was 35.1 years (range, 23 to 51 years).

The characteristics of the study population are summarized in Table 1. Compared with those who did not become pregnant, the women who became pregnant were younger (mean age, 31.8 years vs. 39.6 years; $\mathrm{p}<0.001$ ), and lower frequencies of chemotherapy $(32.1 \%$ vs. $35.2 \%, \mathrm{p}=0.044)$, adju- 
Table 2. Pregnancy outcomes $(\mathrm{n}=992)$

\begin{tabular}{|c|c|c|c|}
\hline Variable & $\begin{array}{l}\text { Successful delivery } \\
\qquad(\mathrm{n}=622)\end{array}$ & $\begin{array}{l}\text { Failed to deliver } \\
\qquad(\mathrm{n}=370)\end{array}$ & p-value \\
\hline Age at cancer diagnosis (yr) & $30.6 \pm 4.0$ & $33.9 \pm 4.7$ & $<0.001$ \\
\hline$\leq 35$ & $553(88.9)$ & $235(63.5)$ & $<0.001$ \\
\hline $36-45$ & $69(11.1)$ & $135(36.5)$ & \\
\hline Age at time of pregnancy (mean) & $34.4 \pm 3.8$ & $37.2 \pm 4.8$ & $<0.001$ \\
\hline$<35$ & $366(58.8)$ & $118(31.9)$ & $<0.001$ \\
\hline$\geq 35$ & $256(41.2)$ & $252(68.1)$ & \\
\hline $\begin{array}{l}\text { Difference between pregnancy age of patients } \\
\text { and age at cancer diagnosis (yr) }\end{array}$ & $3.30 \pm 2.08$ & $2.78 \pm 1.93$ & $<0.001$ \\
\hline Person year $(\mathrm{yr})$ & $6.05 \pm 2.27$ & $5.71 \pm 2.42$ & $<0.001$ \\
\hline \multicolumn{4}{|l|}{ Chemotherapy } \\
\hline Yes & $183(29.4)$ & $135(36.5)$ & 0.021 \\
\hline No & $439(70.6)$ & $235(63.5)$ & \\
\hline \multicolumn{4}{|l|}{ Radiotherapy } \\
\hline Yes & $440(70.7)$ & $262(70.8)$ & 0.981 \\
\hline No & $182(29.3)$ & $108(29.2)$ & \\
\hline \multicolumn{4}{|l|}{ Ovarian preservation (missing $=674$ ) } \\
\hline Yes & $1(0.2)$ & $1(0.3)$ & 0.068 \\
\hline No & $182(29.3)$ & $134(36.2)$ & \\
\hline \multicolumn{4}{|l|}{ Trastuzumab therapy } \\
\hline Yes & $5(0.8)$ & $8(2.2)$ & 0.069 \\
\hline No & $617(99.2)$ & $362(97.8)$ & \\
\hline \multicolumn{4}{|l|}{ Adjuvant hormonal therapy } \\
\hline Yes & $211(33.9)$ & $155(41.9)$ & 0.012 \\
\hline No & $411(66.1)$ & $215(58.1)$ & \\
\hline \multicolumn{4}{|l|}{ Time between surgery and conception (yr) } \\
\hline $0-2$ & $110(17.7)$ & $126(34.1)$ & $<0.001$ \\
\hline$>2$ & $512(82.3)$ & $244(66.0)$ & \\
\hline \multicolumn{4}{|l|}{ SEER stage (missing=385) } \\
\hline Localized & $220(35.4)$ & $121(32.7)$ & 0.074 \\
\hline Regional & 99 (15.9) & $84(22.7)$ & \\
\hline Distant & $5(0.8)$ & $4(1.1)$ & \\
\hline Unknown & $52(8.4)$ & $22(6.0)$ & \\
\hline Missing & $246(39.6)$ & $139(37.6)$ & \\
\hline \multicolumn{4}{|l|}{ Parity } \\
\hline Nullipara & $268(43.1)$ & - & $<0.001$ \\
\hline Primipara or multipara & $83(13.3)$ & $1(0.3)$ & \\
\hline Unknown & $271(43.6)$ & $369(99.7)$ & \\
\hline
\end{tabular}

Values are presented as mean \pm SD or number (\%). SD, standard deviation; SEER, Surveillance, Epidemiology, and End Results.

vant hormonal therapy (36.9 vs. $61, \mathrm{p}<0.001)$, and regional Surveillance, Epidemiology, and End Results (SEER) stage (18.5\% vs. $27.4 \%, \mathrm{p}<0.001)$, which suggested that their cancer was diagnosed at an earlier stage.

\section{Pregnancy patterns of young breast cancer survivors}

Among the 992 women who became pregnant, 622 experi- enced a successful delivery (including 268 nulliparae and 83 primiparae or multiparae), whereas 370 failed to deliver. Those who successfully delivered were younger (mean age, 30.6 years vs. 33.9 years; $p<0.001$ ) and had lower frequencies of chemotherapy $(29.4 \%$ vs. $36.5 \%, \mathrm{p}=0.021)$ and adjuvant hormonal therapy ( $33.9 \%$ vs. $41.9 \%$, $\mathrm{p}=0.012$ ). They were also less likely to have become pregnant $<2$ years after the breast cancer surgery $(17.7 \%$ vs. $34.1 \%, p<0.001)$, compared with 
Table 3. Baseline characteristics of the study cohort according to pregnancy status, after propensity score matching (group 1)

\begin{tabular}{|c|c|c|c|c|}
\hline & $\begin{array}{l}\text { Non-pregnancy } \\
\text { after breast cancer } \\
\qquad(\mathrm{n}=992)\end{array}$ & $\begin{array}{l}\text { Pregnancy after } \\
\text { breast cancer } \\
(n=992)\end{array}$ & p-value & $\begin{array}{c}\text { All } \\
(n=1,984)\end{array}$ \\
\hline Age at cancer diagnosis (yr) & $36.4 \pm 4.4$ & $31.8 \pm 4.5$ & $<0.001$ & $34.1 \pm 5.0$ \\
\hline$\leq 35$ & $788(79.4)$ & $788(79.4)$ & $>0.99$ & $1,576(79.4)$ \\
\hline $36-45$ & $204(20.6)$ & $204(20.6)$ & & $408(20.6)$ \\
\hline \multicolumn{5}{|l|}{ Chemotherapy } \\
\hline Yes & $318(32.1)$ & $318(32.1)$ & $>0.99$ & $636(32.1)$ \\
\hline No & $674(67.9)$ & $674(67.9)$ & & $1,348(67.9)$ \\
\hline \multicolumn{5}{|l|}{ Radiotherapy } \\
\hline Yes & $209(29.2)$ & $209(29.2)$ & $>0.99$ & $580(29.2)$ \\
\hline No & $702(70.8)$ & $702(70.8)$ & & $1,404(70.8)$ \\
\hline \multicolumn{5}{|c|}{ Ovarian preservation (missing $=1,348$ ) } \\
\hline Yes & 0 & $2(0.6)$ & 0.367 & $2(0.3)$ \\
\hline No & $318(100)$ & $316(99.4)$ & & $634(99.7)$ \\
\hline \multicolumn{5}{|l|}{ Trastuzumab therapy } \\
\hline Yes & $7(0.7)$ & $13(1.3)$ & 0.178 & $20(1.0)$ \\
\hline No & $985(99.3)$ & $979(98.7)$ & & $1,964(99.0)$ \\
\hline \multicolumn{5}{|l|}{ Adjuvant hormonal therapy } \\
\hline Yes & $366(36.9)$ & $366(36.9)$ & $>0.99$ & $732(36.9)$ \\
\hline No & $626(63.1)$ & $626(63.1)$ & & $1,252(63.1)$ \\
\hline \multicolumn{5}{|c|}{ Hormone therapy duration (day) } \\
\hline Mean \pm SD & $1,411.8 \pm 625.9$ & $1,061.9 \pm 709.9$ & $<0.001$ & $1,236.8 \pm 691.3$ \\
\hline Median & 1,631 & 1,059 & & 1,459 \\
\hline \multicolumn{5}{|c|}{ Time between surgery and conception (day) } \\
\hline Mean \pm SD & - & $1,176.4 \pm 868.6$ & $<0.001$ & $1,176.4 \pm 868.6$ \\
\hline Median & - & 1,061 & & 1,061 \\
\hline \multicolumn{5}{|l|}{ SEER stage (missing=1,278) } \\
\hline Localized & $41(41.4)$ & $385(59.1)$ & $<0.001$ & $382(49.0)$ \\
\hline Regional & $37(37.4)$ & $183(28.1)$ & & $271(34.7)$ \\
\hline Distant & $3(3.0)$ & $9(1.4)$ & & $22(2.8)$ \\
\hline Unknown & 18 (18.2) & 74 (11.4) & & 105 (13.5) \\
\hline
\end{tabular}

Values are presented as mean \pm SD or number (\%). SEER, Surveillance, Epidemiology, and End Results; SD, standard deviation.

those who failed to deliver (Table 2).

The results for the characteristics of the study population after propensity score matching are presented in Table 3. After matching, our results indicated that the women who became pregnant after treatment for breast cancer had no differences in age at diagnosis, chemotherapy, radiotherapy, ovarian preservation, trastuzumab therapy, adjuvant hormonal therapy, or SEER state, compared with those who did not become pregnant.

\section{Pregnancy and prognosis of young breast cancer sur- vivors}

Compared with women who did not become pregnant subsequent to receiving breast cancer treatment, those who became pregnant had significantly reduced risks of recurrence and death. Compared with those who failed to deliver, those who successfully delivered had a lower risk of recurrence and death (Fig. 2, S1 and S2 Tables). After propensity score matching (Table 4, Fig. 3A, C, E and G), our results showed that women who became pregnant had a significantly reduced risk of recurrence (HR, 0.487; 95\% CI, 0.398 to 0.595$)$. Furthermore, compared with that for women who did not become pregnant, the risk of recurrence was lower for those who successfully delivered (HR, 0.317; 95\% CI, 0.235 to 0.429 ). However, women who failed to deliver did not have a significantly lower risk of recurrence, compared with that for those who did not become pregnant. (HR, 0.760; 


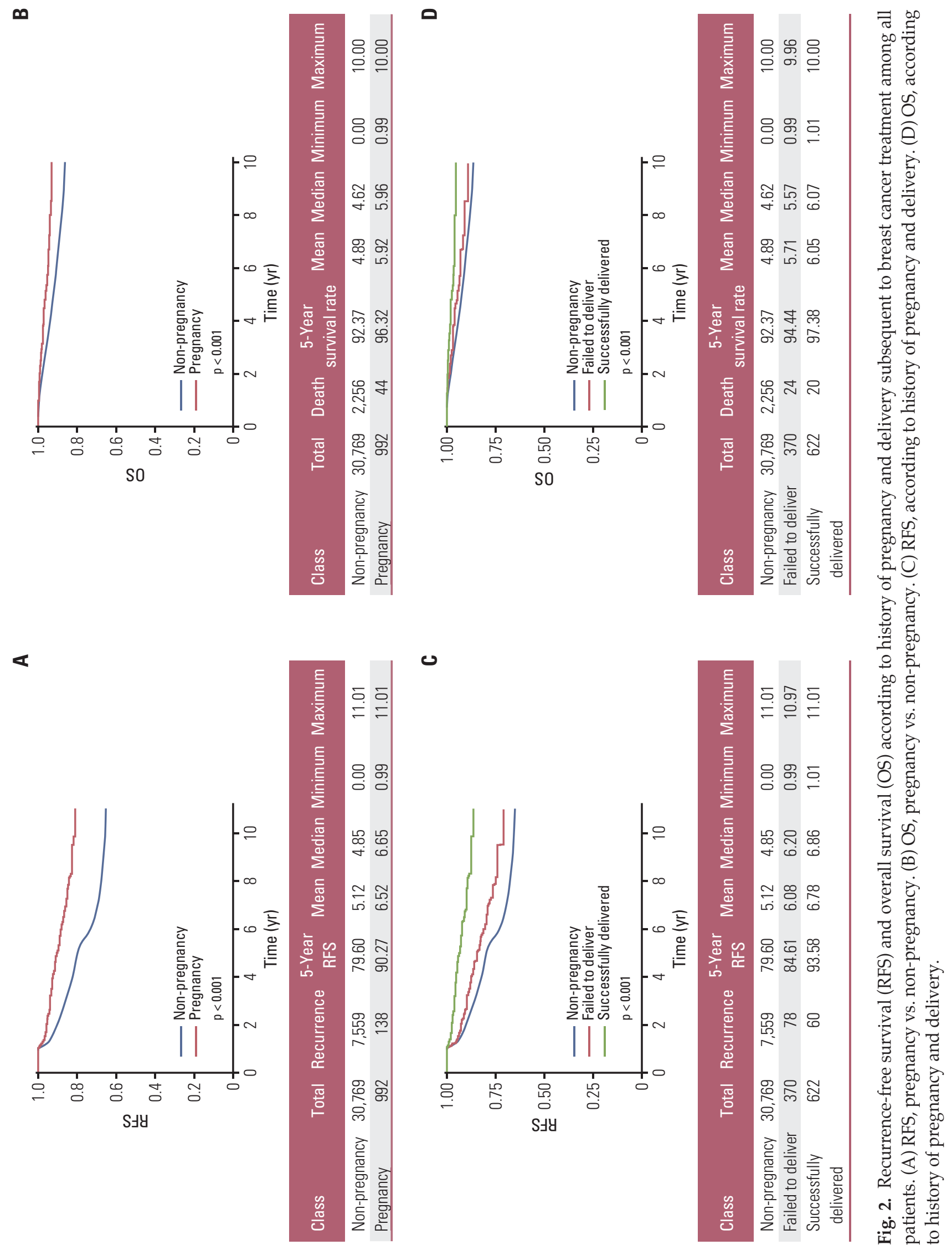


Table 4. Association of subsequent pregnancy on the risk of recurrence, after propensity score matching

\begin{tabular}{|c|c|c|c|c|}
\hline & Hazard ratio & \multicolumn{2}{|c|}{ 95\% Confidence interval } & p-value \\
\hline \multicolumn{5}{|l|}{ Group 1 (n=992) } \\
\hline Non-pregnancy & 1.000 & & & \\
\hline Pregnancy & 0.487 & 0.398 & 0.595 & $<0.001$ \\
\hline \multicolumn{5}{|l|}{ Group $2(n=740)$} \\
\hline Non-pregnancy & 1.000 & & & \\
\hline Failed to deliver & 0.760 & 0.561 & 1.030 & 0.077 \\
\hline \multicolumn{5}{|l|}{ Group $3(n=1,244)$} \\
\hline Non-pregnancy & 1.000 & & & \\
\hline Successful delivery & 0.317 & 0.235 & 0.429 & $<0.001$ \\
\hline \multicolumn{5}{|l|}{ Group $4(n=608)$} \\
\hline Failed to deliver & 1.000 & & & \\
\hline Successful delivery & 0.503 & 0.331 & 0.766 & 0.001 \\
\hline
\end{tabular}

\section{$95 \%$ CI, 0.561 to 1.030 ).}

After propensity score matching, our results showed that women who became pregnant had a significantly reduced risk of death compared with those who did not become pregnant (HR, 0.487; 95\% CI, 0.398 to 0.595) (Table 5, Fig. 3B, D, F and $\mathrm{H})$. Compared with that among women who did not become pregnant, the risk of death was lower among women who successfully delivered (HR, $0.317 ; 95 \% \mathrm{CI}, 0.235$ to 0.429). However, it was not significantly different from that of women who became pregnant but failed to deliver (HR, $0.760 ; 95 \%$ CI, 0.561 to 1.030 ).

\section{Discussion}

We addressed for the first time the outcomes of pregnancy subsequent to a diagnosis of breast cancer among women in Korea. Compared with Western countries, Asian countries have a low incidence of breast cancer and a high proportion of young patients who are able to conceive. Our data showed $38 \%$ of women with breast cancer were younger than 45 years old. Studies of the outcomes of pregnancy after breast cancer require large numbers of patients of childbearing age, so there have been very few such studies in Asian countries. To overcome that hurdle, we used data from the KNHI, KNCR, and KNSO databases, which contain high quality data taken from large cohorts and have been used previously for epidemiologic studies [20-24]. Our results showed that $3.1 \%$ of young women who were diagnosed with breast cancer became pregnant subsequent to the diagnosis, and furthermore, that pregnancy after breast cancer was not detrimental to the oncologic outcome.

Pregnancy rates are approximately $70 \%$ lower among can- cer survivors, compared with the general female population $[27,28]$. In our study, the proportion of women who conceived after receiving breast cancer treatment was lower than the proportion of the general population who conceived. The percentage of women who conceived in our study $(3.1 \%)$ was similar to a Danish population-based study, which found that $3.6 \%$ (371 of 10,295) of women experienced pregnancy [17]. In our study, $622(62.7 \%)$ of the women who became pregnant subsequent to receiving breast cancer treatment delivered successfully. Compared with the women who conceived but did not successfully deliver, those who successfully delivered were younger, waited longer to become pregnant after being treated for cancer, and had a higher frequency of localized SEER stage. Importantly, the outcomes of pregnancy after breast cancer treatment have rarely been investigated in Asian countries. In our study, more than half of the women who became pregnant after receiving breast cancer treatment had a successful delivery.

Concerns about the safety of pregnancy for breast cancer survivors remain high. Health care providers may be uneasy about promoting pregnancy after breast cancer, especially with the current lack of randomized controlled trials, which are ethically difficult to implement. The primary concern regarding pregnancy after breast cancer has been the possible negative impact of pregnancy on the prognosis of patients. Furthermore, the high serum levels of pregnancy-related hormones are known to act as growth factors that affect breast cancer. A large population-based study and a metaanalysis found no difference, however, in recurrence or survival between breast cancer survivors who became pregnant and those who did not become pregnant after breast cancer treatment $[8,17,29,30]$. Recently, a population-based, retrospective cohort study using health administrative databases in Canada was reported [30]. The study analyzed data from 7,553 women with invasive breast cancer, aged 20 to 45 years 


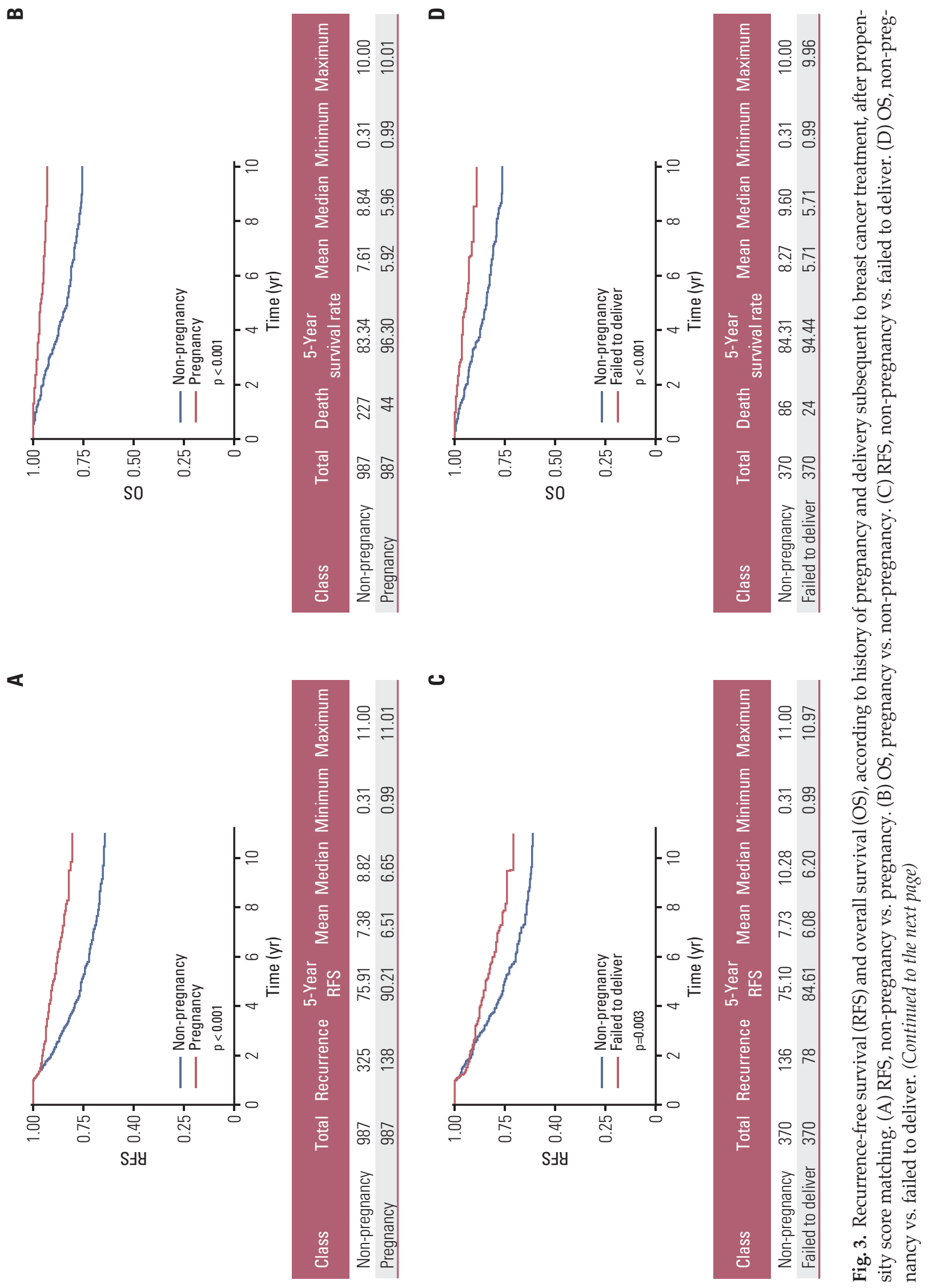




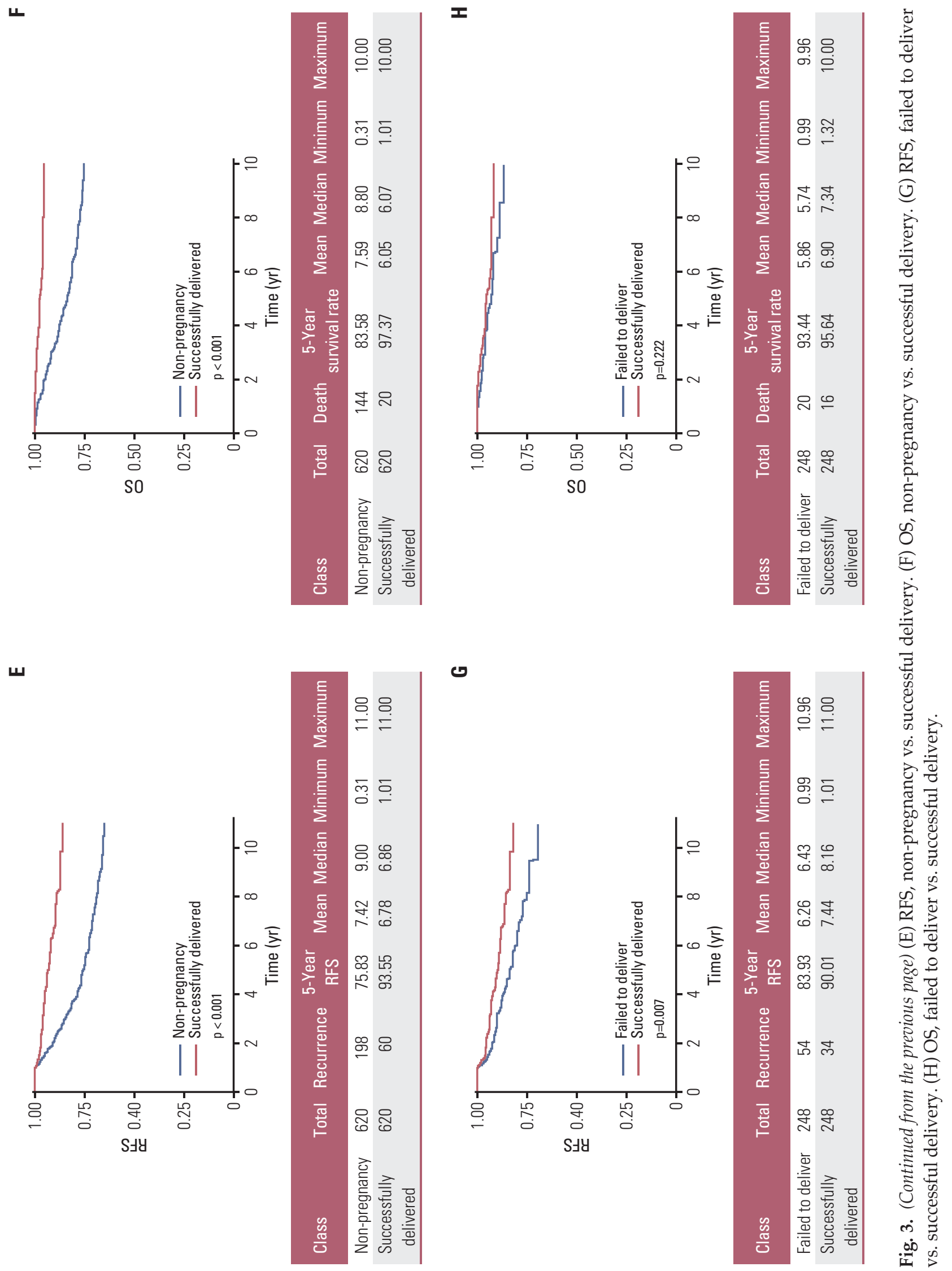


Table 5. Association of subsequent pregnancy on the risk of death, after propensity score matching

\begin{tabular}{|c|c|c|c|c|}
\hline & Hazard ratio & \multicolumn{2}{|c|}{ 95\% Confidence interval } & p-value \\
\hline \multicolumn{5}{|l|}{ Group 1} \\
\hline Non-pregnancy & 1.000 & & & \\
\hline Pregnancy & 0.358 & 0.256 & 0.501 & $<0.001$ \\
\hline \multicolumn{5}{|l|}{ Group 2} \\
\hline Non-pregnancy & 1.000 & & & \\
\hline Failed to deliver & 0.695 & 0.406 & 1.190 & 0.185 \\
\hline \multicolumn{5}{|l|}{ Group 3} \\
\hline Non-pregnancy & 1.000 & & & \\
\hline Successful delivery & 0.184 & 0.113 & 0.299 & $<0.001$ \\
\hline \multicolumn{5}{|l|}{ Group 4} \\
\hline Failed to deliver & 1.000 & & & \\
\hline Successful delivery & 0.656 & 0.338 & 1.272 & 0.212 \\
\hline
\end{tabular}

at the time of diagnosis. The authors found that the 5-year actuarial survival rate was $96.7 \%$ (95\% CI, 0.941 to 0.993 ) for women who became pregnant 6 months or more after their diagnosis of breast cancer, compared with $87.5 \%$ (95\% CI, 0.865 to 0.884 ) for women who did not become pregnant (age-adjusted HR, $0.22 ; 95 \% \mathrm{CI}, 0.10$ to $0.49 ; \mathrm{p}<0.001$ ).

Because of the limitations of the information from the $\mathrm{KNHI}, \mathrm{KNCR}$, and KNSO databases, we could not determine the exact cause of the better survival outcome, which was likely linked to earlier SEER stage and better tumor characteristics. Our results indicated that pregnancy after breast cancer treatment was not related to a poor survival outcome, both before and after propensity score matching. This result was consistent with the results of previous studies $[8,17,29,30]$.

Our study used only data from the KNHI, KNCR, and KNSO databases, so there were several limitations. First, we could not investigate information that was not recorded in the databases. Therefore, we could not know the pregnancy outcomes for women who did not visit the hospital after becoming pregnant and as such, the outcomes of 170 pregnancies were unknown. Second, we did not have information about the clinical and pathologic staging, or pathologic parameters, such as estrogen receptor, progesterone receptor, and HER2 status, which is one of the crucial prognostic factors in breast cancer. Therefore, we could not determine how differences in staging, estrogen receptor, progesterone receptor, and HER2 status between women who became pregnant and those who did not become pregnant affected the prognostic results. Third, information regarding parity is known only for women from the KNHI and KNCR databases who had successful deliveries. Fourth, the registration system for the SEER stage has stabilized since 2006 in Korea, and therefore, a substantial proportion of SEER data was missing in our data. Lastly, exact information about cause of death and recurrence were not included in the KNHI and KNCR databases. Therefore, we had to define recurrence using an alternative definition, and information about recurrence in the population could be unclear.

This is the first study to identify the outcomes of pregnancy after breast cancer in Korea using the KNHI, KNCR, and KNSO databases. Our results showed that 3.1\% of women of childbearing age who were diagnosed with breast cancer became pregnant after receiving treatment for breast cancer, and more than half of those women experienced a successful pregnancy. As our result of study, breast cancer survivors who became pregnant had a better long term survival compared with those who did not become pregnant. Our results suggest that women can plan to conceive after completing breast cancer treatment without fear of negative effects on recurrence.

\section{Electronic Supplementary Material}

Supplementary materials are available at Cancer Research and Treatment website (https://www.e-crt.org).

\section{Conflicts of Interest}

Conflict of interest relevant to this article was not reported.

\section{Acknowledgments}

This study was supported by a grant from the National R\&D Program for Cancer Control, Ministry of Health and Welfare, Republic of Korea (1520240). 


\section{References}

1. Partridge AH, Hughes ME, Warner ET, Ottesen RA, Wong YN, Edge SB, et al. Subtype-dependent relationship between young age at diagnosis and breast cancer survival. J Clin Oncol. 2016;34:3308-14.

2. Chung M, Chang HR, Bland KI, Wanebo HJ. Younger women with breast carcinoma have a poorer prognosis than older women. Cancer. 1996;77:97-103.

3. Winchester DP. Breast cancer in young women. Surg Clin North Am. 1996;76:279-87.

4. Han W, Kim SW, Park IA, Kang D, Kim SW, Youn YK, et al. Young age: an independent risk factor for disease-free survival in women with operable breast cancer. BMC Cancer. 2004;4:82.

5. Kataoka A, Tokunaga E, Masuda N, Shien T, Kawabata K, Miyashita M. Clinicopathological features of young patients ( $<35$ years of age) with breast cancer in a Japanese Breast Cancer Society supported study. Breast Cancer. 2014;21:643-50.

6. Schover LR, Rybicki LA, Martin BA, Bringelsen KA. Having children after cancer. A pilot survey of survivors' attitudes and experiences. Cancer. 1999;86:697-709.

7. Partridge AH, Ruddy KJ. Fertility and adjuvant treatment in young women with breast cancer. Breast. 2007;16 Suppl 2: S175-81.

8. Ives A, Saunders C, Bulsara M, Semmens J. Pregnancy after breast cancer: population based study. BMJ. 2007;334:194.

9. Kranick JA, Schaefer C, Rowell S, Desai M, Petrek JA, Hiatt RA, et al. Is pregnancy after breast cancer safe? Breast J. 2010; 16:404-11.

10. Sankila R, Heinavaara S, Hakulinen T. Survival of breast cancer patients after subsequent term pregnancy: "healthy mother effect". Am J Obstet Gynecol. 1994;170:818-23.

11. von Schoultz E, Johansson H, Wilking N, Rutqvist LE. Influence of prior and subsequent pregnancy on breast cancer prognosis. J Clin Oncol. 1995;13:430-4.

12. Lethaby AE, O'Neill MA, Mason BH, Holdaway IM, Harvey VJ. Overall survival from breast cancer in women pregnant or lactating at or after diagnosis. Auckland Breast Cancer Study Group. Int J Cancer. 1996;67:751-5.

13. Malamos NA, Stathopoulos GP, Keramopoulos A, Papadiamantis J, Vassilaros S. Pregnancy and offspring after the appearance of breast cancer. Oncology. 1996;53:471-5.

14. Kroman N, Jensen MB, Melbye M, Wohlfahrt J, Mouridsen HT. Should women be advised against pregnancy after breastcancer treatment? Lancet. 1997;350:319-22.

15. Mueller BA, Simon MS, Deapen D, Kamineni A, Malone KE, Daling JR. Childbearing and survival after breast carcinoma in young women. Cancer. 2003;98:1131-40.

16. Blakely LJ, Buzdar AU, Lozada JA, Shullaih SA, Hoy E, Smith $\mathrm{TL}$, et al. Effects of pregnancy after treatment for breast carcinoma on survival and risk of recurrence. Cancer. 2004;100:
465-9.

17. Kroman N, Jensen MB, Wohlfahrt J, Ejlertsen B; Danish Breast Cancer Cooperative Group. Pregnancy after treatment of breast cancer: a population-based study on behalf of Danish Breast Cancer Cooperative Group. Acta Oncol. 2008;47:545-9.

18. Shin HR, Won YJ, Jung KW, Kong HJ, Yim SH, Lee JK, et al. Nationwide cancer incidence in Korea, 1999 2001; first result using the national cancer incidence database. Cancer Res Treat. 2005;37:325-31.

19. Jung KW, Won YJ, Kong HJ, Oh CM, Cho H, Lee DH, et al. Cancer statistics in Korea: incidence, mortality, survival, and prevalence in 2012. Cancer Res Treat. 2015;47:127-41.

20. Jee SH, Ohrr H, Sull JW, Yun JE, Ji M, Samet JM. Fasting serum glucose level and cancer risk in Korean men and women. JAMA. 2005;293:194-202.

21. Jee SH, Suh I, Kim IS, Appel LJ. Smoking and atherosclerotic cardiovascular disease in men with low levels of serum cholesterol: the Korea Medical Insurance Corporation Study. JAMA. 1999;282:2149-55.

22. Jee SH, Sull JW, Park J, Lee SY, Ohrr H, Guallar E, et al. Bodymass index and mortality in Korean men and women. N Engl J Med. 2006;355:779-87.

23. Park SM, Lim MK, Jung KW, Shin SA, Yoo KY, Yun YH, et al. Prediagnosis smoking, obesity, insulin resistance, and second primary cancer risk in male cancer survivors: National Health Insurance Corporation Study. J Clin Oncol. 2007;25:4835-43.

24. Park SM, Yun YH, Kim YA, Jo M, Won YJ, Back JH, et al. Prediagnosis body mass index and risk of secondary primary cancer in male cancer survivors: a large cohort study. J Clin Oncol. 2016;34:4116-24.

25. Lee J, Lee JS, Park SH, Shin SA, Kim K. Cohort Profile: The national health insurance service-national sample cohort (NHIS-NSC), South Korea. Int J Epidemiol. 2017;46:e15.

26. Pearce N. Analysis of matched case-control studies. BMJ. 2016;352:1969.

27. Peccatori FA, Azim HA Jr, Orecchia R, Hoekstra HJ, Pavlidis $\mathrm{N}$, Kesic V, et al. Cancer, pregnancy and fertility: ESMO Clinical Practice Guidelines for diagnosis, treatment and followup. Ann Oncol. 2013;24 Suppl 6:vi160-70.

28. Stensheim H, Cvancarova M, Moller B, Fossa SD. Pregnancy after adolescent and adult cancer: a population-based matched cohort study. Int J Cancer. 2011;129:1225-36.

29. Luo M, Zeng J, Li F, He L, Li T. Safety of pregnancy after surgical treatment for breast cancer: a meta-analysis. Int J Gynecol Cancer. 2014;24:1366-72.

30. Iqbal J, Amir E, Rochon PA, Giannakeas V, Sun P, Narod SA. Association of the timing of pregnancy with survival in women with breast cancer. JAMA Oncol. 2017;3:659-65. 